\title{
Estratégias individuais de proteção à saúde: um estudo da adesão ao sistema de saúde suplementar
}

\author{
Individual health protection strategies: \\ a study on adherence to the supplementary \\ health system
}

\begin{abstract}
This article discusses low-income users' adhesion to private health insurance companies. This article considers the macrostructural analysis insufficient for the understanding of this phenomenon and takes into account the existence of a "field of possibilities" in which people make choice and decisions. Ten users of health insurance companies were interviewed. People's representations about health systems were analyzed through three dimensions-quality, access, and safety. In this sense, the analysis aimed to understand the choices logic in relation to the acquisition of a private health insurance. Finally, it is observed that the representations about the vulnerability of one's own health condition guides the protection's strategy - to use public health system or buy private health insurance - practiced by subjects.
\end{abstract}

Key words Private health insurance, Public health system, Social representations
Resumo $O$ artigo discute a adesão aos planos de saúde entre indivíduos de camadas populares. Parte do princípio de que a análise macroestrutural é insuficiente para a compreensão desse fenômeno, e interpreta a ação social tomando como princípio a existência de um campo de possibilidades dentro do qual os indivíduos realizam escolhas e tomam decisões. A discussão baseia-se em pesquisa qualitativa, realizada pelo autor, para a qual foram entrevistados dez informantes que contrataram serviços de empresas do sistema de saúde suplementar. Analisando, a partir de três dimensões - qualidade, acesso e segurança - as representações presentes nos discursos dos entrevistados, procura compreender a lógica subjacente às escolhas em relação à contratação de um plano de saúde. Observa-se que as representações sobre a vulnerabilidade da própria saúde possuem um papel central para a estratégia de proteção - SUS versus planos de saúde - posta em prática pelo sujeito.

Palavras-chave Planos de saúde, Saúde suplementar, SUS, Representações sociais

\footnotetext{
1 Departamento de Ciências Sociais, Escola Nacional de Saúde Pública, Fundação Oswaldo Cruz. Av. Leopoldo Bulhões 1480/9o andar, Manguinhos, 21041-210, Rio de Janeiro RJ. farias@ensp.fiocruz.br
} 


\section{Introdução}

Fatores de ordem estrutural, externos aos indivíduos - posição de classe, por exemplo - impõem limites objetivos às suas ações e limitam suas possibilidades de escolha, dentre outras formas, pelas condições econômicas a que os submetem. Contudo, há que se recusar explicações simplistas, em que o campo de possibilidades no qual se movimentam os indivíduos seja ignorado e suas ações reduzidas mecanicamente ao produto das coerções econômicas estruturais. As análises baseadas exclusivamente na determinação das estruturas econômicas são insuficientes para que se compreenda o fenômeno da adesão aos planos de saúde, objeto deste artigo.

Como podemos compreender o fato de que indivíduos com capacidade financeira similar realizam escolhas diferenciadas quanto à decisão de comprar proteção à saúde por meio do sistema suplementar? Seguindo o mesmo rastro de problemas, devemos ainda nos perguntar: quando as determinações econômicas constituem um fator constrangedor, mas não totalmente impeditivo, que elementos podem explicar a decisão de contratar ou não um plano de saúde? Essas são as principais perguntas que motivam a nossa investigação.

A análise da adesão ao sistema de saúde suplementar requer, até certo ponto, algumas considerações sobre o sistema público de saúde. As dificuldades de acesso e a baixa qualidade atribuída a este último têm sido consideradas como condições que propiciaram o crescimento dos planos e seguros de saúde no Brasil (Faverette Filho \& Oliveira, 1990; Médici, 1991). Sejam concebidas como características objetivas ou como percepções subjetivas, as condições de acesso e a qualidade do atendimento nos serviços públicos de saúde são variáveis importantes para a compreensão do crescimento do sistema suplementar nas décadas de 1980 e 1990. Por outro lado, as interpretações histórico-estruturais que analisam o esgotamento do modelo estatal-privatista de assistência médicoprevidenciário no final da década de 1970 e início dos anos 80 complementam a compreensão do contexto no qual esse processo se inicia (Luz, 1991; Oliveira \& Teixeira, 1989). Sendo assim, a crise que se instaura no início da década de 1980 força o setor privado de assistência à saúde a empreender um processo de "modernização" capitalista, passando este a atuar na conquista e expansão de mercados consumido- res entre os segmentos insatisfeitos com a assistência estatal e aptos a custear outras alternativas de proteção à saúde (Faria, 1995, 1997).

A relação de causalidade entre as dificuldades de acesso e a baixa qualidade no sistema público de saúde e o crescimento da adesão ao sistema de saúde suplementar tem se mantido como uma tese plausível. No entanto, nota-se uma carência de investigações empíricas que explicitem os mecanismos através dos quais essa cadeia causal se atualiza. Para ultrapassar o âmbito das proposições gerais faz-se necessário, primeiramente, reconhecer o caráter heterogêneo da clientela que consome os serviços da saúde suplementar e a partir daí buscar os processos e eventos intermediários que por trajetórias distintas conduzem os sujeitos para essa modalidade de proteção à saúde.

A maneira pela qual construímos teóricometodologicamente o objeto de investigação conduziu-nos a um caminho no qual a incorporação do sujeito como elemento ativo impôsse como condição necessária. Contudo, admitir uma limitação ao alcance das determinações estruturais não significou apenas ceder ao argumento da contingencialidade, antes implicou a compreensão dos mecanismos através dos quais se organizam as escolhas em um campo de possibilidades.

\section{Questões metodológicas}

Neste estudo, a segmentação interna da clientela dos planos e seguros de saúde foi considerada através de dois recortes. O primeiro refere-se à forma de adesão e distingue duas maneiras pelas quais os indivíduos se vinculam aos planos e seguros de saúde. Classificamos as modalidades de adesão em compulsória ou voluntária, referindo-se a primeira às situações em que o vínculo empregatício do indivíduo aparece como um fator de indução à adesão, e a segunda, àquelas decorrentes da iniciativa própria e da ação particular dos sujeitos. $\mathrm{Na}$ primeira forma de adesão (compulsória), os custos são subsidiados, total ou parcialmente, pelo empregador e esta se deve mais a uma circunstância que envolve coletivamente o conjunto de trabalhadores do que a uma escolha ou decisão do sujeito em particular, tendendo este a certa passividade ante as ações que o envolvem. $\mathrm{Na}$ adesão voluntária, o indivíduo reassume o papel de sujeito da ação; busca no mercado, por motivação e iniciativa própria, o ser- 
viço que deseja consumir e responsabiliza-se integralmente pelo pagamento à empresa contratada. Os custos de oportunidade envolvidos em um e outro caso são diferentes e é lícito supor que os elementos que motivam as ações e orientam as escolhas também o sejam.

O segundo recorte utilizado para caracterizar a segmentação da clientela do sistema de saúde suplementar baseia-se na própria segmentação de classe presente no conjunto dos seus clientes. Membros de classes sociais distintas relacionam-se de forma diferenciada com os cuidados à saúde (Boltanski, 1984), seja pela percepção de suas necessidades, pelas expectativas que alimentam ou pelos recursos de que dispõem. Deve-se então supor que a trajetória que conduz esses indivíduos aos planos e seguros de saúde é igualmente afetada por tais diferenças.

A partir do recorte mencionado, delimitamos para estudo o segmento de clientela composto por indivíduos das camadas populares que se vincularam a algum plano de saúde por meio de adesão voluntária. Neste segmento específico procuramos compreender o modo pelo qual as condições de acesso e qualidade oferecidas pelo Sistema Único de Saúde efetivamente se relacionam com contratação dos serviços da saúde suplementar. Através da técnica de entrevistas semi-estruturadas foi identificado um conjunto de representações sobre o SUS e os planos de saúde, assim como valores e representações relacionados às necessidades e expectativas de proteção à saúde encontradas entre esse indivíduos. Foram realizadas dez entrevistas seguindo todas o mesmo roteiro de questões básicas ao qual eram acrescidas outras questões, se e quando necessário, no sentido de aprofundar ou esclarecer os pontos abordados.

Os indivíduos que participaram da pesquisa na qualidade de informantes são residentes de dois bairros populares do município de Petrópolis, cidade de aproximadamente duzentos e setenta mil habitantes, localizada na região serrana do Estado do Rio de Janeiro, a sessenta quilômetros de distância da capital. Os critérios estabelecidos para a seleção dos informantes foram os seguintes: a) menos de 12 anos de escolaridade; b) baixa qualificação profissional; c) situação ocupacional de pouco prestígio social; d) ser cliente de plano de saúde, contratado e pago direta e voluntariamente, sem intermediação de empregadores ou agentes similares; e) ter sido usuário do sistema público de saúde durante algum período de suas vidas.

\section{Qualidade, acesso e segurança nas representações dos sistemas de saúde}

Através do conteúdo das entrevistas podemos identificar e analisar um conjunto de percepções e representações que informam a elaboração de juízos sobre o sistema público e o sistema de saúde suplementar. Pode-se assim verificar em detalhes onde reside, para os sujeitos entrevistados, a suposta superioridade da assistência prestada pelo plano de saúde em relação à que é oferecida pelo SUS. O caráter avaliativo presente no discurso dos informantes, em parte incitado pelo roteiro de entrevista, remete-se de forma clara a duas dimensões tradicionalmente abrangidas em qualquer avaliação de sistemas ou serviços de saúde, a dizer, qualidade e acessibilidade. Contudo, uma terceira dimensão - segurança - emerge do sentido dos discursos complexificando a compreensão da interação material e simbólica entre os sujeitos e os sistemas de saúde. A noção de segurança surge então como um terceiro ponto de apoio na análise do material empírico. A dimensão relativa à segurança se constitui através da contraposição das representações sobre qualidade e acesso às necessidades e expectativas de proteção requeridas por cada indivíduo, sendo estas últimas correlacionadas aos ricos aos quais eles imaginam estar expostos.

Através do trinômio qualidade-acesso-segurança estrutura-se uma espécie de filtro que opera a mediação entre o sistema e serviços de saúde e seus usuários. Postulamos para essas dimensões - aqui tratadas como categorias de análise - uma função mediadora, o que significa compreendê-las como constitutivas de uma estrutura de classificação, antes que um conjunto de atributos definidos e estáticos.

\section{A qualidade do atendimento}

O momento de contato do cliente/usuário com o profissional médico constitui uma experiência fundamental na formação do juízo que o sujeito elabora sobre a qualidade do atendimento que lhe é ofertado por um dado sistema de saúde ou pelas unidades que o integram. Do médico espera-se não apenas prescrição eficaz, mas, também, um tipo de interação humanizada e personalizada, na qual o paciente se sinta alvo de dedicação pelo profissional. A exigência de uma certa cumplicidade entre os dois pólos da relação aparece de forma recorrente 
nos depoimentos dos entrevistados. A interação interpessoal constitui, sob a ótica do paciente um aspecto central da sua avaliação sobre qualidade da atenção (Donabedian, 1984).

Não possuindo conhecimento que permita avaliar do ponto de vista tecno-científico a intervenção médica, os pacientes tendem a valorizar especialmente a relação interpessoal, que se estabelecida, com o médico enquanto este último realiza os procedimentos necessários ao diagnóstico e à prescrição terapêutica. Sendo assim, a cordialidade do médico, as demonstrações de interesse pela singularidade de cada caso, a disponibilidade de tempo para examinar, dar explicações e ouvir o paciente compõem um conjunto de requisitos que informam junto com a eficácia da intervenção, observada a posteriori - a avaliação que o paciente elabora sobre a qualidade do atendimento. O cumprimento desses requisitos não objetiva apenas suprir as necessidades emocionais ou afetivas dos pacientes; antes, essa exigência integra um cálculo racional, coerente com a representação das condições ideais ao pleno exercício da competência tecno-científica dos médicos. Como demonstra Boltanski (1984), quanto maior a distância cultural e econômica que separa o médico do seu paciente, maior é a relevância que o contato interpessoal assume na avaliação que o paciente realiza sobre a qualidade da intervenção a que se está expondo.

Os critérios interpessoais adotados na avaliação que os pacientes elaboram, embora sejam insuficientes para uma avaliação profunda, remetem a aspectos que não podem ser desconsiderados na atenção à saúde. A tese do desapossamento do saber clínico pelos leigos não pode ser utilizada para deslegitimar os meios pelos quais estes conseguem manter algum controle, ainda que insipiente, sobre o poder exercido sobre eles.

O tempo de duração da consulta médica, por exemplo, pode não ser, segundo critérios "técnicos", um bom indicador da competência e qualidade da intervenção clínica, contudo através dele revelam-se aspectos importantes da dimensão interpessoal do atendimento. Uma consulta que dure trinta minutos não será necessariamente mais eficaz do que outra que dure apenas dez. Obviamente, a formação e a experiência do profissional médico e os recursos de que ele dispõe seriam indicadores mais seguros para a garantia da qualidade. Todavia, a questão não está posta dessa forma. O que se coloca é que um profissional médico, seja qual for sua formação e experiência, terá oportunidade de realizar um melhor atendimento ao paciente na medida em que dispuser de um intervalo de tempo adequado para efetuar a investigação, o diagnóstico e a prescrição terapêutica.

A contraposição, pelos entrevistados, entre a qualidade de atendimento médico do sistema público e dos planos de saúde não reflete uma polarização no que tange à qualidade dos profissionais médicos. Ou seja, não se trata, na visão do informante, de uma concentração de maus profissionais no sistema público em oposição a uma concentração de bons profissionais nos planos de saúde. As reclamações referentes ao atendimento médico no sistema público de saúde foram, via de regra, acompanhadas pela crítica de trabalho a que estão submetidos os profissionais. Assim, por exemplo, a superlotação dos ambulatórios é vista como uma das causas do pequeno tempo de duração das consultas e da pouca atenção dispensada pelos médicos a seus pacientes. A consulta no sistema público de saúde é caracterizada pelos entrevistados como um evento, cujo tempo de duração frustra o paciente na medida que provoca a suspeita de que os procedimentos de investigação e diagnóstico foram abreviados ou mesmo negligenciados. Ademais, não devemos ignorar o direito dos pacientes de obter uma explicação objetiva e compreensível dos processos patológicos que atingem seu corpo, assim como das terapêuticas que lhe são aplicadas, procedimentos estes que também demandam tempo.

\section{Fátima 51 g-1}

Você chega no INPS, quantas vezes aconteceu comigo, e eu vejo até com meus filhos. Os médicos às vezes nem põem a mão no doente. Passam receitas e... vai comprar o remédio. Não sabe se as pessoas às vezes está com uma pneumonia, não sabe, não sabe o problema da pessoa. Já pelo plano não. (...) Não acredito que o INPS atende bem. Não acredito, sabe por que? - não é falar mal dos médicos - é que muitas vezes, muitas pessoas, então não têm... o médico chega ali, tá cinqüenta pessoas. Como é que ele vai atender bem, né?

\section{Débora 34 g-2}

Ele [o médico do plano de saúde] tem um tempo maior pra ficar, pra falar com você, pra te examinar, pra..., pra tudo. Eu acho que o médico do plano de saúde tem um tempo maior pra ficar 
com você do que o médico do SUS. (...) Quando eu preciso ir ao médico eu gosto que o médico..., eu tenho que ver que ele está interessado em saber daquilo que eu estou precisando, entendeu, do meu problema. O médico tem que estar interessado - "Você está sentindo isso, tá sentindo aquilo? De onde começou?" Tem várias perguntas que o médico do plano de saúde te faz que o médico do SUS não te faz, sabe.

\section{Joana 53 g-1}

Eu tenho muita experiência, porque muitas vezes eu fui [no SUS] e... interessante que alguns médicos bons, médicos bons. Mas com excesso de trabalho, de muitas pessoas... eles não atendiam a gente assim como deveriam, né, igual um plano de saúde; com mais atenção, com mais tempo no consultório. Quer dizer, não tem como, não é por ele, é: pelo "excesso de pessoas".

Do médico espera-se esforço máximo para que seja eficaz a sua intervenção. Os entrevistados assinalam a expectativa de serem minuciosamente examinados, ouvidos e inquiridos sobre tudo que possa de alguma maneira estar relacionado com o seu problema, para que só então o médico profira seu diagnóstico e prescreva a terapêutica.

Com base nos juízos críticos que elaboram em relação ao atendimento médico, os pacientes podem recusar-se a acatar suas determinações. Sua vida ou o bem-estar encontra-se, ainda que parcialmente, subjugada à perícia e ao empenho do médico. Assim, as demonstrações de esforço e interesse, por cada caso clínico e por cada sujeito em particular, constituem a experiência a partir da qual o paciente elabora seu juízo crítico quanto ao atendimento. Em um segundo momento, esse juízo pode ser modificado em função do grau de eficácia da intervenção, mas aqui interessa-nos fundamentalmente a análise da relação médico/paciente.

Prevalece a visão de que o sistema público de saúde, além de sobrecarregar seus médicos com um número de atendimentos superior àquele que poderia ser realizado nos padrões de qualidade desejados, remunera-os mal, comparativamente ao rendimento que poderiam obter em consultórios próprios. Dessa maneira, os entrevistados baseiam seu argumento na crítica ao sistema e tendem a eximir os médicos de responsabilidade pela má qualidade do atendimento prestado.

\section{As condições de acesso}

As condições de acesso - ou a acessibilidade na nomenclatura adotada por Donabedian (1984) - se referem ao grau de facilidade ou dificuldade com que os indivíduos se deparam no momento em que buscam obter a atenção médica ofertada pelos serviços de saúde. Tais dificuldades ou facilidades podem ser provenientes de vários fatores, tais como, a localização dos serviços, o grau de adequação qualitativa entre oferta e demanda, os procedimentos e requisitos necessários à admissão do paciente, o tempo de espera que antecede o atendimento etc. Como vemos, as condições de acesso não se limitam à relação quantitativa entre a oferta e a demanda, embora esse seja um dos seus aspectos centrais. Fatores geográficos, organizacionais, financeiros e culturais compõem o mosaico a partir do qual devemos compreendê-las.

O usuário/cliente pode elaborar severas críticas em relação ao acesso num dado serviço de saúde e, simultaneamente, considerar de boa qualidade a atenção ofertada pelo mesmo ou, ao contrário, identificar facilidade quanto ao acesso, mas ter críticas à qualidade. Em alguns casos é a própria excelência da qualidade de uma unidade de serviços que provoca um fluxo de demanda superior a sua capacidade de absorção pelo lado da oferta, provocando reflexos negativos sobre o acesso. É importante ressaltar que há entre os entrevistados razoável clareza quanto ao conteúdo de cada uma das dimensões.

O contraste entre as condições de acesso no sistema público de saúde e nos planos de saúde é, seguramente, o ponto mais consensual quando comparamos o discurso dos diversos entrevistados. A espera por longas horas em filas que começam a se formar em meio à madrugada para conseguir uma senha - distribuída em número limitado - que permite o atendimento por um médico é uma imagem descrita por todos os nossos informantes quando se referem ao sistema público de saúde. A procura pelo atendimento médico implica, assim, significativo esforço e desgaste para um indivíduo que muitas vezes já se encontra física e psicologicamente debilitado. Não bastasse esse cansativo "rito de iniciação" à condição de paciente, deve-se ainda considerar o fato de que após horas de espera o candidato à paciente pode não conseguir uma senha, ou pior, ao consegui-la pode, após outra jornada de espera, descobrir que o médico por ele aguardado não comparecerá ao trabalho naquele dia. 


\section{Joana 53 g-1}

Eu tinha que sair às cinco horas da manhã para ir para fila do INAMPS, chegava lá, vinte fichas só. - "Acabou". Aí ficava um tempão, uma, duas horas na fila e... pra vinte pessoas. Muita gente saía revoltada. E muita gente com problemas sérios, gravíssimos, que não podia esperar.

\section{Leonora 55 g-1}

Às vezes chega a dormir na fila, né, pra conseguir número, porque precisa mesmo. Dependendo do médico... Aqui mesmo, tem vezes da pessoa ir pra fila às duas horas da manhã pra conseguir o médico que a pessoa quer.

\section{Betânia 65 g-1}

É aquela dificuldade, você tem que ir pra lá às quatro horas da manhã pra conseguir médico. Quer dizer que a dificuldade é muito grande né, você com plano de saúde tem muito mais conforto.

\section{Fernanda $29 \mathrm{~g}-2$}

É... porque depois que a pessoa se adapta a um plano de saúde o conforto é grande... a facilidade é enorme. Na hora que você chega você é atendido. Telefona, - "Oh, vou marcar para tal hora com o médico tal". Você chegou lá na hora que marcou, você é atendido.

Embora as condições de acesso não expliquem por si só o deslocamento de clientela do sistema público para os planos de saúde, tratase de uma situação real, que influencia as escolhas e preferência em relação ao setor privado. Pode-se observar nas entrevistas que, no que tange às condições de acesso, os planos de saúde oferecem a seus clientes um nível de conforto e comodidade inimagináveis nas "representações” que, em algum grau, são engendradas por suas próprias experiências no sistema público. Trocar o desconforto decorrente de horas de permanência em uma fila pela comodidade de uma simples ligação telefônica é, inegavelmente, um diferencial de valor positivo. A facilidade de acesso aos serviços oferecida pelos planos exerce um efeito persuasivo na cooptação de clientela, sobretudo na população que tem o SUS como referência objetiva de assistência médica.

Para além das questões de comodidade ou desconforto, as condições de acesso identifica- das com os planos de saúde agregam um outro elemento ainda mais importante para os entrevistados, a garantia de que obterão atendimento médico quando necessário.

\section{Segurança}

Em qualquer sociedade e período histórico as pessoas estão expostas, tanto individual quanto coletivamente, a fenômenos que ameaçam sua reprodução material e social, sendo que a percepção dessas ameaças assim como a natureza e abrangência das mesmas ganham contorno diferenciados no tempo e no espaço. À possibilidade dessas ameaças potenciais atingirem efetivamente uma dada realidade, provocando-lhe alterações funestas, chamamos risco. A sensação de segurança, por sua vez, está diretamente relacionada às percepções e representações sobre o volume e a intensidade dos riscos aos quais esses indivíduos e coletividades encontram-se expostos, em síntese, à representação de sua vulnerabilidade.

Do ponto de vista dos indivíduos, o sentimento de segurança é abalado, em maior ou menor grau, de acordo com as representações que eles conferem aos riscos, difusos ou pontuais, que se associam ao contexto no qual estão inseridos. A própria idéia de segurança, como algo passível de ser identificado e sentido como tal pelo sujeito, só se torna possível através de uma condição ou sentimento que a ela se contraponha. Assim, segurança e risco são categorias indissociáveis, que produzem seus sentidos na relação existente entre elas. Podemos afirmar que a segurança pressupõe certa crença na estabilidade e previsibilidade do ambiente (do contexto) de ação, de modo a manter mais ou menos sob controle os riscos potenciais (Giddens, 1991).

A noção de segurança diferencia-se bastante da de proteção embora haja algum grau de relação entre ambas. A idéia de proteção, largamente utilizada nos estudos sobre Welfare State e sobre políticas sociais de uma forma geral, faz menção à construção de mecanismos concretos que visam atenuar ou eliminar as conseqüências do desenvolvimento capitalista, social e politicamente reconhecidas como negativas. Nesse sentido, a proteção é um elemento externo ao sujeito e possui, via de regra, uma materialidade própria; não é uma experiência subjetiva, mas sim um estado de coisas (leis, instituições, procedimentos, ações etc.). Os meca- 
nismos de proteção relacionam-se com a noção de segurança na medida que compõem ou modificam o contexto no qual os indivíduos se inserem objetivando atenuar os riscos potenciais. Mas a sensação de segurança é produto da mediação subjetiva operada pelo sujeito posto em contato com os eventos e processos que caracterizam o contexto específico em que ele está inserido, dentro do qual a existência de algum mecanismo de proteção constitui apenas um entre vários elementos.

A segurança é uma experiência subjetiva que reflete a interação entre o conjunto de características particulares de cada sujeito (socioculturais, econômicas, psicológicas etc.) e um dado contexto. Este conjunto de características individuais já é, em si, um produto complexo derivado de diversas outras inserções em diferentes contextos sociais. Os sujeitos não apenas participam de contextos sociais diferentes como também participam diferentemente de um mesmo contexto. Daí decorre o fato de que a segurança, como experiência do indivíduo, não seja algo que possua um conteúdo fixo, idêntico ou facilmente intercambiável para diferentes sujeitos sociais.

O material de pesquisa revela, por um lado, a segurança produzida pela adesão ao plano de saúde e, por outro, a insegurança presente na condição de usuário do sistema público de saúde. Contudo, essas representações não são absolutas; podem apresentar variações se tomarmos como referência diferentes entrevistados, ou mesmo, se considerarmos um mesmo entrevistado em diferentes momentos do seu discurso. Por exemplo, um usuário de um plano de saúde que oferece cobertura limitada à área geográfica do seu município terá posicionamentos diversos acerca da segurança que desfruta, conforme se imagine dentro ou fora da área geográfica de cobertura.

Mas, de uma forma geral, a associação plano de saúde/segurança por oposição à associação sistema público de saúde/insegurança constitui o padrão "normal” dessas representações. A oposição entre certeza e contingência é estruturante nas representações que associam a segurança (ou insegurança) a uma modalidade ou sistema de proteção à saúde.

\section{Fátima 51 g-1}

É que... a diferença é a seguinte... é o que eu falei, tem pessoas que tem sorte. Vai no INPS, é que o médico atendeu, atendeu bem. E outras pessoas vai lá... não tem sorte, né. Esse meu fitho aí, ele fala: - 'Ah, mãe, o INPS é muito bom'. Nenhum deles quiseram [ter plano], só minha filha. (Grifos do autor)

\section{Débora 34 g-2}

Eu agradeço a Deus que eu tive sorte de encontrar [no SUS] bons médicos, boas enfermeiras, que me deram total atenção. (Grifos do autor)

\section{Fernanda $29 \mathrm{~g}-2$}

Pelo menos eu sei que qualquer coisa que eu sentir a qualquer hora, eu posso sair que eu vou ser atendida em algum lugar, num hospital... Porque, pelo SUS você já corre o risco né de ficar na porta de um hospital e ninguém te atender. Então te dá mais segurança sim. (Grifos do autor)

\section{Débora 34 g-2}

Eu fico meses sem usar médico, mas eu pago. Não acho desvantagem porque quando eu preciso ir eu sei que eu posso contar e eu vou. (...) Eu me sinto mais segura porque eu sei que eu posso contar com meu médico, eu posso chegar e telefonar pra ele, não tem ele tem o assistente; eu posso ir direto para o hospital do Plano quem tem sempre médico lá também, e eles entram em contato com o meu médico já, que me acompanha. E se eu fosse contar com o SUS eu sei que não é bem assim (risos).

\section{Leonora 55 g-1}

Meu medo..., eu tenho esse problema de pressão alta, entendeu. De repente tiver um problema qualquer, na mesma hora... é só ligar para o médico ele está mandando ir, ou ele está mandando ir para o hospital que ele está indo também. Ainda há poucos dias aí eu passei mal, com uma dor que eu não estava agüentando mais. Ainda falei com a minha filha: ou eu estou tendo um infarto ou uma pneumonia. Aí elas ligaram para o médico e ele disse: - "Vai para o hospital que eu já estou indo". Quer dizer, resultado, foi um atendimento fora de sério. Eu cheguei lá, dali a pouco ele chegou também.

A experiência vivida no uso do sistema público de saúde remete sempre a um navegar no espaço da contingência, no qual elementos pouco previsíveis ou controláveis definem o destino do sujeito. A recorrência da idéia de "sorte" reforça a existência de uma representação ne- 
gativa do sistema público de saúde mesmo nos episódios em que este tenha respondido satisfatoriamente às demandas pelo usuário.

As experiências e expectativas desses sujeitos como cliente/usuário de um plano de saúde remetem, por sua vez, a um ambiente de certezas, de previsibilidade, onde o espaço da sorte ou da contingência é extremamente reduzido. É justamente nestes aspectos que repousa a sensação de segurança desfrutada pelos informantes.

A noção de segurança, tornada uma das dimensões analíticas do estudo, nos oferece importantes subsídios para a compreensão da adesão aos planos de saúde no segmento social pesquisado. A contraposição dos relatos que se referem ao sistema público e aos planos de saúde revela uma situação dicotômica, tal como observamos nas análises relativas à qualidade do atendimento e às condições de acesso.

Em geral, as representações acerca destas outras duas dimensões (qualidade e acesso) reaparecem como pano de fundo quando analisamos a segurança que os sujeitos manifestam em relação ao uso dos distintos sistemas de saúde. Contudo, a segurança não deve ser vista como um mero reflexo das percepções negativas atribuídas às outras dimensões. As representações sobre segurança são substancialmente afetadas pelas especificidades dos sujeitos, e os próprios juízos sobre a qualidade do atendimento e as condições de acesso são, em alguma medi$\mathrm{da}$, afetados por elas.

Incorporar a segurança como uma dimensão de análise implica que se leve em consideração as condições e características constitutivas da particularidade dos sujeitos e não apenas os atributos - identificados de forma objetiva ou subjetiva - do sistema. A relevância que os problemas encontrados no sistema público assumem na conformação da segurança percebida dependerá então das condições e características constitutivas da realidade material e simbólica dos sujeitos que os interpretam. Isto que dizer que, por um lado, os problemas existentes no sistema público de saúde abalam de forma diferenciada a percepção da segurança pelos sujeitos, uma vez que dependerá de como estes representam a sua condição de vulnerabilidade ante os riscos que ameaçam a saúde. E, por outro lado, a própria problematização que engendra as representações negativas do sistema público não pode ser isolada do efeito resultante das representações que os sujeitos elaboram sobre si mesmo, especialmente em relação à condição de vulnerabilidade de sua saú- de. Vale lembrar que a identificação com uma condição de maior vulnerabilidade é uma característica central identificada nos indivíduos que compõem do grupo pesquisado.

\section{Organizando escolhas em um campo de possibilidades: a adesão ao sistema de saúde suplementar}

Com já mencionamos anteriormente, a razão de um indivíduo contratar um plano de saúde não se esgota no fato de o mesmo deter a capacidade econômica para a compra desse serviço. É óbvio que para contratar tal serviço no âmbito do mercado é preciso, em primeiro lugar, possuir os meios monetários para arcar com seus custos e, nesse sentido, as determinações econômicas condicionam as possibilidades de escolha ou decisão. Contudo, somente se não houvesse condições econômicas mínimas para viabilizar o custo da adesão - a despeito de toda e qualquer ação de racionamento de gastos em prol da priorização do "bem" saúde - o indivíduo estaria privado da possibilidade de escolha. Apenas nesse caso extremo seria falso o cogito da condição ativa do sujeito, que realiza escolhas e toma decisões, implícita inclusive nos casos de não-adesão.

A idéia de que o indivíduo possui um espaço de movimentação no qual desfruta de liberdade na orientação de suas ações sempre esteve presente nas ciências sociais. Este ponto de vista pode ser apresentado de forma mais ou menos radical por autores diversos, de acordo com a maneira como cada um desses autores concebe a amplitude do espaço de liberdade do indivíduo e a força coercitiva das estruturas sociais. Durante algum tempo, a polarização entre as abordagens estruturalistas e as abordagens fundamentadas no individualismo metodológico levaram a um sectarismo teórico prejudicial à análise da realidade social. Atualmente há esforços na sociologia no sentido de compatibilizar diferentes abordagens em prol de análises mais holistas. É seguindo essa orientação que Elster (1994) busca delimitar as fronteiras entre a liberdade e a coerção a partir da conjugação entre os desejos e as oportunidades dos indivíduos: Um esquema simples para uma ação é vê-la como resultado final de duas operações filtradoras sucessivas. Começamos com um grande conjunto de todas as ações abstratamente possíveis que um indivíduo poderia empreender. $O$ primeiro filtro é constituído por todas as coer- 
ções físicas, econômicas, legais e psicológicas com que o indivíduo se depara. As ações consistentes com essas coerções formam seu conjunto de oportunidades. O segundo filtro é um mecanismo que determina qual ação do conjunto de oportunidades será de fato executada. Nesta exposição os principais mecanismos a serem considerados são a escolha racional e as normas sociais (Elster, 1994).

No plano do senso comum é muito forte a idéia de que somente as pessoas impossibilitadas de pagar um plano de saúde não aderem a este sistema. Aceita-se, desta forma, a falsa premissa de que o desejo de adesão é igualmente compartilhado por todos os indivíduos e que apenas as diferenças de oportunidades fazem com que alguns indivíduos não contratem esses serviços. Se é verdade que a adesão voluntária a um plano de saúde é condicionada pela capacidade financeira - nesse caso, equivalente à oportunidade - do indivíduo ou sua família de arcar com os custos, não é menos verdade que possuir esta capacidade não determina automaticamente a adesão. Caso contrário, estaríamos erroneamente convertendo a pré-condição de realização da ação na motivação que a desencadeia, orienta e dá sentido.

Outro aspecto freqüentemente ignorado pelo senso comum é que indivíduos ou famílias com similar capacidade financeira podem apresentar grandes diferenças quanto à posição dos seus gastos, sendo estes últimos modelados por prioridades organizadas segundo combinações particulares de necessidades e valores. Isto significa que mesmo indivíduos ou famílias com capacidade financeira bastante limitadas podem em determinadas circunstâncias priorizar o consumo de um determinado bem - proteção à saúde, por exemplo - em detrimento do consumo de outros bens.

O segmento social pesquisado, embora incluído no mercado consumidor, detém recursos escassos para a aquisição de bens e serviços já incorporados, com naturalidade, ao padrão de consumo de outros segmentos sociais. Entre os indivíduos entrevistados, a existência de gastos regulares direcionados à contratação de serviços de saúde já é, por si só, reveladora de significativa organização de prioridades, dentro da qual o privilegiamento da proteção da saúde implica, via de regra, sacrifício sistemático de outras necessidades ou desejos. A prioridade dada à proteção à saúde torna-se mais visível nesses indivíduos em função da escassez de recursos econômicos a que estão submeti- dos, pois para um individuo ou núcleo familiar que dispusesse de maiores recursos financeiros o gasto com contratação de serviços de saúde teria, em termos relativos, um peso menor, não implicando tão diretamente o racionamento ou abdicação sistemática da realização de outras necessidades ou desejos.

\section{Débora 34 g-2}

Quem precisa e tem condições também de pagar um planode saúde; quem corta assim... Deixa de fazer, né, as coisas que... Você corta muitas coisas, você deixa de fazer. Eu, pelo menos, eu deixo de fazer muitas coisas por causa do plano de saúde que eu tenho que pagar. Eu sei que eu tenho esse compromisso pra pagar todo mês. Mas eu deixo, sabe, e não me arrependo de deixar de fazer pra pagar o plano de saúde.

\section{Fátima 51 g-1}

Então eu achei que precisava. E minha filha precisava; então eu combinei com ela.

- "Vamos combinar aí; a gente paga, cada um paga um pouco". Porque pobre é triste, né. Pobre tem que tá fazendo vaquinha pra conseguir, né.

\section{Joana 53 g-1}

Olha, eu já estou reduzindo [despesas]. Muitas coisas... Em primeiro, em primeiro lugar o plano, porque é uma coisa que realmente a gente precisa.

Podemos observar pelo discurso dos entrevistados o contexto econômico restritivo no qual realizam suas escolhas e verificar como, de fato, o direcionamento regular para a contratação de serviços de saúde é revelador da posição de destaque ocupada pela proteção à saúde.

A pesquisa demonstrou que no segmento social estudado a adesão voluntária aos planos de saúde nos revela algo mais do que a insatisfação com os serviços públicos de saúde. A representação do SUS como um serviço no qual predomina a baixa qualidade de atendimento e os obstáculos ao acesso é apenas o ponto de partida para que os indivíduos escolham a proteção dos planos. Contudo, num contexto de recursos escassos esta escolha só se efetiva quando a "ampliação" dos mecanismos de proteção à saúde torna-se uma necessidade fundamental ao equilíbrio da segurança, fazendo com que a contratação de um plano de saúde assuma uma 
posição de destaque na ordem de prioridades ou escala de preferência desses indivíduos.

A adesão a umplano de saúde é desencadeada - na maioria das vezes - por um evento de doença. A auto-representação do sujeito como um ser vulnerável, frágil ou debilitado aumenta a sua insegurança ante o SUS, espaço no qual a proteção à sua saúde remete ao domínio da contingência. A identificação de um ambiente ou contexto no qual os riscos que ameaçam a saúde assumem uma intensidade superior a que poderia ser considerada "normal" produz a necessidade de ampliação dos mecanismos de proteção como forma de resguardar a segurança e a saúde do indivíduo.

Fatores como gênero e idade afetam de forma importante as representações acerca dos riscos relativos a saúde, atribuindo-se maior vulnerabilidade às mulheres e aos idosos. A representação da condição de vulnerabilidade ante os riscos justifica a maior ou menor necessidade de contratação de um plano de saúde, e é responsável em grande medida pela posição que o consumo desse serviço ocupará na ordem de prioridades ou escala de preferência dos sujeitos.

\section{Débora 34 g-2}

Antes eu pensava assim. - "Ah não, vou pagar plano de saúde pra que? Não preciso, estou bem, não sinto nada. Não vou pagar plano de saúde nenhum; o dinheiro que eu vou gastar com plano de saúde eu vou comprar roupa, sapato, sair, vou me distrair, vou viajar". Porque é um dinheirinho que dá pra você fazer alguma coisa. Eu pensava assim.

\section{Leonora 55 g-1}

Tem gente que realmente... principalmente uma pessoa nova, né, que de repente teve algum problema e teve que ir no médico, é preferível ela ir lá [no SUS] pegar número e ser atendida no outro dia do que ela desembolsar todo mês uma quantia, né. (...) Aqui mesmo tem vizinho que tem possibilidade de pagar mas tem o carro, então de repente... não tem necessidade, né, de... E tem saúde também, né. Isso tudo vai muito da pessoa ter saúde.

\section{Leonora 55 g-1}

Ele não sente nada [o marido]. Ele não esquenta, entendeu. Já está com sessenta anos e graças a Deus ele... E às vezes a gente fala e tudo.
Já teve um plano aí que não era tão caro, eu quis fazer pra ele e ele não quis. Ele não quis, e... Diz que não precisa, não sente nada. Não precisa ir a médico, né. Quer dizer, não tem aquela coisa de ter que ir a médico. Ele nunca...

\section{Fátima 51 g-1}

Porque geralmente a saúde de minha filha e eu são mais... Porque os outros... Por exemplo, meu esposo, ele nem resfriado ele toma. Então ele acha que pra quê, pra quê que eu vou ter plano se eu não preciso. É assim que ele fala.

\section{Joana 53 g-1}

Eu tenho um tratamento também, de varizes, que todo mês eu dependo do médico, todo mês; não posso faltar, então é o dia marcado certinho. Eu trato já há quatro anos. Não pode deixar de ir. Então [o plano] é uma coisa que eu não posso deixar de pagar mesmo.

\section{Betânia 65 g-1}

Eu tenho que ficar com o plano. Porque se eu tenho que fazer exames periódicos de três em três meses, então..., pra fazer eu teria que continuar com plano.

Parte dos entrevistados já havia possuído planos de saúde oferecidos como "benefício" pelas empresas nas quais os próprios ou seus respectivos cônjuges, filhos ou pais trabalhavam. $\mathrm{O}$ rompimento do vínculo empregatício, fosse por demissão ou aposentadoria, faria cessar imediatamente a cobertura do plano de saúde tanto ao titular quanto a seus dependentes. A perda do plano empresarial tinha como conseqüências mais imediatas a interrupção de tratamentos médicos que estavam em curso e a necessidade de trocar de médico, pois muitas vezes o profissional com o qual a pessoa se tratava não trabalha no SUS. A adesão voluntária ao plano, quando pôde ser viabilizada economicamente, foi o caminho encontrado para que se evitasse essas conseqüências indesejadas. As representações sobre a vulnerabilidade, aliadas aos constrangimentos econômicos, tornam a utilização do SUS aceitável para algumas dessas pessoas e a adesão voluntária ao plano imprescindível pra outras.

O plano empresarial, uma vez que é substancialmente subsidiado pelo empregador, chegando em alguns casos a ter custo zero para o empregado, não subordina a adesão a um critério de necessidade identificado pelo indiví- 
duo, ao contrário do que acontece quando o custo recai integralmente sobre o usuário. Observamos que a passagem do plano empresarial para a adesão voluntária tende a excluir alguns membros do núcleo familiar - principalmente nos contextos em que os constrangimentos econômicos são maiores - e que os planos contratados tendem a ser de padrão inferior ao que era oferecido pelo empregador, porém da mesma operadora, para evitar a perda de carência e manter a continuidade da relação com os médicos anteriores procurados.

A comodidade de acesso e as diferenças positivas quanto ao atendimento, contrapostas às dificuldades enfrentadas no SUS, acentuam e consolidam uma visão negativa em relação a este último. A partir do momento em que desfrutam de um plano de saúde, o retorno à condição de usuário do SUS representa um retrocesso no padrão de consumo, assinalando também um declive da posição do sujeito nas hierarquias materiais e simbólicas que organizam a sociedade.

\section{Considerações finais}

De forma bastante sintética pontuaremos os principais resultados da pesquisa que originou este artigo. A incorporação da dimensão simbólica - valores e representações - na compreensão do deslocamento de clientelas do SUS para os planos de saúde permitiu identificar elementos importantes para a análise deste fenômeno e, esperamos, contribuir para a construção de novas abordagens sobre a saúde suplementar no Brasil, setor que hoje atende a aproximadamente $25 \%$ da nossa população.

a) De uma forma geral, a superioridade dos planos de saúde em relação ao SUS é admitida pelos entrevistados nas três dimensões analíticas trabalhadas pela pesquisa: qualidade da atenção, condições de acesso e segurança.

b) As representações dos entrevistados sobre o sistema público de saúde não constituem, no entanto, um conjunto unívoco ou monolítico. Podem, portanto, apresentar conflitos e contradições aparentes, seja no discurso de diferentes informantes, seja em momentos distintos do discurso de uma mesma pessoa. É através do contexto em que os enunciados se inscrevem que podemos compreender e analisar os juízos que contêm.

c) Apesar de atribuírem baixa qualidade ao SUS, os entrevistados isentam de culpa os mé- dicos que trabalham no sistema público de saúde. Percebemos uma representação "sacralizada" da profissão médica, que tende a inibir representações mais críticas do comportamento desses profissionais na relação que estabelecem com seus pacientes. Os baixos salários e o excesso de pacientes são utilizados pelos informantes como justificativas para a falta de atenção ou interesse que, segundo as suas representações, tendem a prevalecer entre os médicos do SUS.

d) Na opinião dos informantes, os médicos do SUS, de forma geral, não diferem dos médicos dos planos de saúde em relação à competência técnica. Os entrevistados demonstram inclusive ter clareza quanto ao fato de que muitos profissionais trabalham em ambos os sistemas.

e) A dificuldade de acesso aos serviços públicos de saúde torna-se um obstáculo maior ou menor de acordo com a freqüência com que se necessita utilizar os mesmos, podendo ser relevada pelas pessoas “jovens”, pelas que "têm saúde" ou pelas que possuem condições específicas capazes de amenizar os obstáculos ao acesso (por exemplo: morar muito perto da unidade de saúde, possuir carro para se deslocar até a unidade etc.).

f) O fato de a pessoa ter sido beneficiária de um "plano empresarial” é um elemento significativo quando analisamos a adesão voluntária. A adesão compulsória (planos empresariais) estaria, em alguma medida, contribuindo para a construção e disseminação de novos padrões de consumo em relação aos cuidados médicos em meio aos estratos sociais de menor poder aquisitivo.

g) A adesão a um plano de saúde é, via de regra, associada no tempo a um momento em que a pessoa identifica sua saúde como debilitada ou frágil. A necessidade de utilização imediata e/ou constante dos cuidados médicos atua como detonador na adesão voluntária aos planos de saúde.

h) As representações associadas ao gênero e à idade constituem valores fundamentais na interpretação da relação segurança/risco e determinam uma escala de prioridades familiar na compra de proteção. Os homens, mesmo os de mais idade, são tidos como indivíduos de melhor saúde (ou expostos a menores riscos) que as mulheres, assim como os jovens são considerados menos vulneráveis que os velhos. Independentemente da ocorrência objetiva de uma distribuição desigual de riscos entre estes grupos, devemos considerar que a atenção pri- 
vilegiada às mulheres e idosos é uma característica culturalmente construída.

i) Raramente todos os membros da família possuem planos de saúde. Em condições de recursos escassos a escolha dos familiares que terão plano de saúde segue visivelmente uma escala de prioridades construída com base nos critérios de necessidade/vulnerabilidade que informam as percepções acerca da segurança.

\section{Referências bibliográficas}

Boltanski L 1984. As classes sociais e o corpo (2a ed.). Graal, Rio de Janeiro.

Donabedian A 1984. La calidad de la atención médicadefinición y métodos de evaluación. La Prensa Mexica, México, D.F.

Elster J 1994. Peças e engrenagens das ciências sociais. Relume-Dumará, Rio de Janeiro.

Farias LO 1995. As novas articulações entre o público e o privado no setor saúde. Trabalho apresentado no Congresso Brasileiro de Ciências Sociais em Saúde/ ABRASCO, Curitiba, (mimeo).

Farias LO 1997. Consolidação do setor privado. Trabalho apresentado no V Congresso Brasileiro de Saúde Coletiva e V Congresso Paulista de Saúde Pública. Águas de Lindóia, (mimeo).

Faverette Filho P \& Oliveira PJ 1990. A universalização excludente: reflexões sobre as tendências do sistema de saúde. Revista Dados, 33(2).

Giddens A 1991. As conseqüências da modernidade. Editora da Universidade Estadual Paulista, São Paulo.
Giovanella L e Fleury S 1996. Universidade da atenção à saúde: acesso como categoria de análise. In Eibenschutz C (org.). Política de saúde: o público e o privado. Ed. Fiocruz, Rio de Janeiro.

Luz MT 1991. Notas sobre as políticas de saúde no Brasil de "Transição Democrática": anos 80. Revista Physis, 1(1).

Médici AC 1991. A medicina de grupo no Brasil. Série Desenvolvimento de Políticas Sociais, no 1. Organização Pan-Americana de Saúde 9 (OPAS), Brasília.

Oliveira JAA \& Teixeira SMF1989. (Im)Previdência Social: 60 anos de história da previdência no Brasil (2a ed). Vozes-ABRASCO, Petrópolis-Rio de Janeiro.

Ribeiro ACT \& Souza HS 1995. Saúde e comunicação: faces contemporâneas da gestão da sociedade. In Pitta AMR (org.). Saúde e comunicação - visibilidades e silêncio. Hucitec-ABRASCO. São Paulo-Rio de Janeiro.

Samuelson PA 1983. Fundamentos da análise econômica. In Samuelson Coleção Os Economistas. Abril Cultural, São Paulo.

Velho G 1999. Individualismo e cultura: notas para uma antropologia da sociedade contemporânea (5a ed.). Jorge Zahar Editora, Rio de Janeiro. 